Revista Iberoamericana, Vol. LXXX, Núm. 246, Enero-Marzo 2014, 205-225

\title{
RETRATO DEL JOVEN POETA
}

\author{
POR \\ Sergio Delgado \\ Université de Bretagne-Sud
}

\section{EL TRABAJO EN MARCHA}

Un poeta de edad más bien avanzada, sintiéndose “un poco sucio”, abandona las letras y la ciudad y en busca del lugar donde supone pueden estar sus Orígenes, con confesada ingenuidad interroga ese "rostro de Ella, no escrito" (Ortiz Obra completa 547). Otro poeta, en este caso un viejo Li Po, se despierta en el jardín de madrugada y, sacudiéndose el polvo y la borrachera de la víspera, se dirige hacia la casa a dormir la mona. Entra en silencio, discreto, tratando de pasar desapercibido y de no tener que "calzarse, trabajosamente, otra vez, la máscara / aunque más no fuese por una noche, una sola noche” (Saer, El arte de narrar 38). ¿Quién es “ella”, aquello no escrito donde el poeta espera encontrar, en cierto modo, su propia juventud? ¿En qué consiste esa juventud y cuál es en definitiva ese rostro que la máscara recubre con dificultad?

Demasiadas preguntas, quizás, como para un comienzo. No esperamos agotarlas porque el personaje del joven, que cumple sin duda un rol decisivo en ese gran teatro que fue la literatura occidental de la primera mitad del siglo xx, es un nudo que no termina nunca de desatarse. Ser joven resultó ser -resulta todavía- muchas cosas: una buena estrategia para una determinada posición ante el sistema literario, la excusa o si se quiere la coartada para una dinámica vanguardista (el juvenilismo como sinónimo de lo nuevo) e incluso la réplica justa para poder salir de la escena, haciendo mutis por el foro. En todos estos casos ser joven implica esa máscara y esa ubicación en un impreciso escenario (dentro o fuera de la ciudad, dentro o fuera de la casa). Ser poeta, al menos en los casos que ahora nos interesa estudiar, implica necesariamente la toma de conciencia de una puesta en situación. Nos desentenderemos, en cierto modo, de los aspectos públicos del problema y buscaremos más bien el rostro de nuestros poetas en la intimidad, cuando se miran en el espejo.

Voy a referirme a dos proyectos distintos, en los que me encuentro trabajando actualmente, donde estas imágenes de "joven poeta" se suceden, se superponen y, de alguna manera, en épocas y contextos distantes, se encuentran y dialogan. En primer 
lugar esbozaré algunos problemas relativos a la preparación de una segunda edición, revisada y ampliada, de la Obra completa de Juan L. Ortiz. ${ }^{1}$ En segundo lugar, sacaré algunas primeras conclusiones del proyecto de un volumen con los Borradores de poesía de Juan José Saer, ${ }^{2}$ donde se reunirán los poemas inéditos que se encuentran en sus cuadernos, carpetas y, probablemente, una parte de sus traducciones de poesía; pondremos estos textos en relación con la escritura de El arte de narrar.

Me referiré entonces a algo que está en marcha, brindando resultados inevitablemente parciales. ${ }^{3}$ La noción de "progreso" tiene aquí su sentido porque entendemos que este tipo de trabajo crítico nunca termina de concluir y conlleva además, sobre todo en esta etapa, su parte de riesgo y azar. La precariedad es un dato que quisiera transmitir, en la medida de lo posible, sin disimulo. Espero que estas reflexiones, que me ayudan a pensar mi propio trabajo, puedan ser de alguna utilidad para quienes enfrentan problemas similares. No hablo entonces desde lo hecho sino de lo que se está haciendo o por hacer. Y con todo esto quisiera significar por lo menos dos cosas.

En primer lugar que el trabajo crítico se elabora siempre en un contexto personal, incluso en los casos en los que se trabaja en equipo. Esta afirmación, que no presupone ninguna novedad teórica, es una noción indispensable para discutir el carácter que debe investir una edición crítica, sobre todo en nuestro dominio iberoamericano. Por distintas razones, dictadas probablemente por la falta de costumbre, se percibe en nuestro medio una suerte de superstición que considera que una edición crítica es algo definitivo y, en muchos casos, una suerte de fatalidad. Hay que desmantelar esta superstición. Nunca se termina esta tarea crítica, que conlleva su parte de subjetividad -vuelvo a insistir sobre este punto- $\mathrm{y}$ que se plantea entonces a partir de las certezas provisorias, los gustos individuales e incluso las perplejidades de ese lector especializado que es el crítico.

En segundo lugar, quisiera significar también que el trabajo crítico, aunque se haga -con convicción o ingenuidad- a la luz del dictado de sus materiales, debe estar alimentado por una, dos o tres -no muchas más- preguntas o hipótesis elementales. Siempre tiene que haber, como motivación, por lo menos una de esas preguntas.

1 La primera edición fue realizada en 1996 (Universidad Nacional del Litoral, Santa Fe), de la cual se hicieron varias reimpresiones. En el marco de un proyecto de la Universidad Nacional del Litoral, a partir del año 2011 trabajamos, junto con Francisco Bitar, en la idea de una segunda edición. Es tiempo de revisar y ampliar este trabajo, tanto en lo que hace al texto como al dispositivo crítico que lo acompaña.

2 En el marco del trabajo de un equipo dirigido por Julio Premat sobre el Fondo de manuscritos de Juan José Saer, se prepara la edición de cuatro volúmenes de textos inéditos, uno de los cuales estará dedicado a la poesía. Dos de esos cuatro se publicaron en 2012 y 2013 bajo el título de Papeles de trabajo. El tercero, Poemas. Borradores inéditos 3, acaba de salir.

3 Debo agradecer la invitación y el entusiasmo de Daniel Balderston, organizador de las jornadas de trabajo de Pittsburgh, en marzo de 2011, donde fue leído este trabajo, así como a los valiosos aportes de los participantes de dichas jornadas, que han sido integrados a esta versión del trabajo. Un agradecimiento particular a la generosa relectura de María Laura Bocaz y de Julio Premat.

\footnotetext{
Hevista Iberoamericana, Vol. LXXX, Núm. 246, Enero-Marzo 2014, 205-225 ISSN 0034-9631 (Impreso) ISSN 2154-4794 (Electrónico)
} 
Preguntas que no busquen, simplemente, obtener una respuesta que las resuelva, sino que en su apertura y permanencia, puedan orientar la lectura de un corpus complejo de manuscritos. En nuestro caso, además, vamos a aplicar una misma pregunta a dos trabajos distintos -que, como intentaremos demostrarlo, dialogan íntimamente-, lo que multiplica geométricamente ese espacio de riesgo pero que puede también, si la pregunta es pertinente, ser el hilo que nos señale la salida del laberinto o esa bala, si acaso se nos permite la expresión, que mate dos pájaros de un mismo tiro.

Volvamos a las preguntas, entonces: ¿cuál es ese rostro de poeta que encubre toda escritura poética? Y más precisamente todavía: ¿cuál es ese rostro de joven poeta que siempre se pierde y siempre se reconstruye? ¿De qué manera -si pudiéramos pensar la pregunta en estos términos- la escritura es un espejo donde el poeta busca su propia juventud, es decir la fuerza de su origen? ¿Cómo dar cuenta, finalmente, de ese "espejo" en el marco de una edición crítica?

EL JOVEN POETA

La figura del "joven poeta” funda gran parte de la poesía moderna, marcando la historia de la literatura con personajes-poetas-jóvenes hoy ya emblemáticos, desde la nostalgia del "poeta maldito" en Arthur Rimbaud ("Jadis, si je me souviens bien, ma vie était un festin où s'ouvraient tous les cœurs", 125) hasta la "inocencia” del artista de Portrait of the Artist as a Young Dog de Dylan Thomas. Figuras de poetas que plantean una relación muy particularmente intensa entre poesía y juventud. En muchos casos se trata además de poetas que mueren o dejan de escribir jóvenes, como si poesía y madurez resultaran términos irreconciliables. En la literatura hispanoamericana hay una frondosa genealogía de la que se nutre el modernismo. ${ }^{4}$

Quien mejor ha planteado el problema es Rilke en sus Cartas a un joven poeta, un libro compuesto por diez cartas dirigidas a Franz Kappus, un joven poeta (jungen Dichter) que interroga al poeta mayor en relación con el problema del reconocimiento. Es decir: cómo puede el joven, que se inicia en la poesía, reconocerse a sí mismo como poeta, cómo logra conocer el destino poético que debe asumir, dado que ningún espejo del mundo le permite ver ese rostro. La respuesta de Rilke es terminante: "buscá la necesidad que te lleva a escribir: examiná si ella hunde sus raíces en lo más profundo de tu corazón. Confesate, a vos mismo: ¿morirías si te fuera prohibido escribir?”. Si la respuesta no admite equívocos -y no puede haberlos puesto que no hay términos medios en le concepción rilkeana-, el poeta debe “construir toda su vida según esa necesidad”.

4 El juvenilismo modernista presenta una constelación emblemática de poetas que mueren jóvenes, como Julián del Casal a los 30 años, José Asunción Silva a los 31 y Julio Herrera y Reissig a los 35. Leopoldo Lugones exclama, en el prólogo a Lunario sentimental: “Tengo treinta y cuatro años, y he vivido”.

Revista Iberoamericana, Vol. LXXX, Núm. 246,
ISSN 0034-9631 (Impreso) 
Esto quiere decir, en primer lugar, que no hay mirada exterior -no sirven aquí como prueba ni el éxito ni el reconocimiento literario-y que el joven poeta sólo puede descubrir su rostro poético mirándose a sí mismo, en su interior, reconociendo en sí mismo y por sí mismo esa necesidad que lo lleva a escribir. Esto quiere decir también, en segundo lugar, lo que es en cierto modo la contracara del mandato planteado por Rilke, que la clave de esa necesidad o destino del poeta se encuentra anclada en la juventud.

Borges, en el prólogo de 1969 a una redición de Fervor de Buenos Aires, donde se refiere al trabajo de revisión y corrección de dicha edición en relación con la primera, de 1923, afirma: "he sentido que aquel muchacho que en 1923 lo escribió ya era esencialmente-¿qué significa esencialmente?-el señor que ahora se resigna o corrige”. Mucho se ha hablado de esta contradicción: ¿¿son acaso lo mismo aquel muchacho de la escritura y este hombre de la corrección?, ¿que sigue significando, ahora que volvemos a leer ese prólogo, aquella esencia invencible del joven?

Seguimos dando vuelta sobre las mismas preguntas respecto al significado de esa "esencia” juvenil que se conserva, inalterable, como una suerte de dimensión poética paralela.

\section{UN JOVEN ENTRERRIANO}

Juan L. Ortiz publicó su primer poemario, El agua y la noche, en 1933, a los 37 años de edad. Es decir que desde el inicio de su obra se presentó como un escritor "adulto", en plena conciencia de su destino de poeta, que con sabiduría iría y fue completando, a partir de esta primera entrega, los capítulos de En el aura del sauce, el libro que reúne toda su obra.

Hay testimonios, sin embargo -quizás un tanto exagerados-, de que Ortiz, niño prodigio en la pequeña Gualeguay de principios del siglo XX, a los 9 años escribía y publicaba versos. Es decir que hay un gran vacío (Alfredo Veiravé, habla de los "años del silencio"), durante el cual en realidad Ortiz construye, re-escribiendo y sobre todo olvidando, su propia génesis de poeta. Al plantear la primera edición de la Obra completa, pudimos aproximarnos a este silencio, elaborando algunas hipótesis a partir del descubrimiento de un Cuaderno Borrador donde se encontraban los poemas que llamamos el Protosauce. Estos poemas fueron considerados por Ortiz en la "selección" que dio origen a ese primer libro de la obra, pero por alguna razón se descartaron, permaneciendo aparte como las astillas que caen al costado de la mesa de trabajo del escritor, puesto que nunca fueron publicados, aunque tampoco eliminados totalmente. Estos poemas, en realidad, sólo responden parcialmente a la problemática de los años del silencio, dado que el Protosauce se inicia en 1924 (año del casamiento del poeta, de su entrada en la vida civil, que deja atrás la época que él llamaba de su "vida bohemia") y no varían notablemente, en su tema y su forma, de los poemas de El agua y la noche.

Revista Iberoamericana, Vol. LXXX, Núm. 246, Enero-Marzo 2014, $205-225$
ISSN 0034-9631 (Impreso) 
En varios de los reportajes que se le hicieron en los años 70, es decir cuando aparece En el aura del sauce, la primera edición de su obra reunida, Ortiz vuelve a sus comienzos para rememorar o reconstruir su juventud y delinea, con una determinada homogeneidad, el ciclo de estos “años del silencio”, que es el de su formación. En el más completo de sus testimonios, el reportaje que brinda a Juana Bignozzi, al preguntársele por la "historia de su poesía” Ortiz responde: “mientras permanecía en Gualeguay, era una poesía de imprecación rebelde como se le decía entonces, pero en Buenos Aires me encontré con muchas cosas que me hicieron envainar la espada” (Bignozzi 127).

El poeta reconstruye así, a grandes trazos, el carácter de aquel joven poeta de la ciudad de Gualeguay y en este relato el viaje a Buenos Aires, hacia 1913, aparece como decisivo. En Buenos Aires, Ortiz permanece dos o tres años y allí se encuentra con "muchas cosas" que lo llevan a decidir la vuelta a Entre Ríos. A esta decisión, es decir el "envainar la espada", en el poema "Gualeguay" la denomina también la retirada. Decisión estratégica, en la cual resuena un determinado contexto bélico, dado que en la misma pesa una opción ante las vanguardias literarias de la época, pero también, si se quiere, una clave personal.

Este esquema, que se repite con algunas variantes en otros testimonios de Ortiz, también de los años 70, impone una reconstrucción retrospectiva del proceso de iniciación. En lo que respecta al contexto propiamente poético, como veremos en el fragmento que sigue, el mismo está determinado por el modernismo rioplatense que sigue los pasos de Darío, ${ }^{5}$ principalmente el de Herrera y Reissig de Los peregrinos de piedra y el de Lugones de Los crepúsculos del jardín:

[E]ra un período de ejercicio literario y retórico. De leer y admirar... la cosa artificiosa entonces, pero que no pude eludir, pero ya estaba el paisaje, me acuerdo: "silva el viento hace frío y el turbio firmamento en silencio se angustia... silba el viento y sollozan románticas campanas...” me acuerdo de “...el silencio de mi íntimo tormento fantasmea paisajes... las lejanas infiltraciones de la noche esfuman los perfiles como un ala cansada la tarde se hunde en vacilante ritmo y jardines sonámbulos (Lugones, ¿¿se da cuenta?) perfuman el ambiente dormido”. Es Herrera y Reissig y Lugones. (Bignozzi 127)

El poeta reconstruye entonces el escenario de su iniciación poética, en función del viaje a Buenos Aires, en torno a la pérdida y recuperación del paisaje natal. Y la lenta y agónica formación, el "ejercicio literario y retórico", tienen un sentido en la confrontación con el centro metropolitano. Así podemos recuperar, solamente de una manera parcial y fugaz, ese trabajo de iniciación: fragmentos de poemas, de versos,

5 Hablamos del paso de Darío por el Río de la Plata en varios sentidos -sentido poético pero también histórico y geográfico, considerando los años de su estancia en Buenos Aires-y pensamos también en su muerte, que se produce en 1916.

Revista Iberoamericana, Vol. LXXX, Núm. 246, Enero-Marzo 2014, 205-225 
de ritmos, que permanecen en la memoria del poeta. Podemos percibir algunos versos heptasílabos, quizás hemistiquios de alejandrinos ("silba el viento, hace frío / y el turbio firmamento / en silencio se angustia... / silba el viento y sollozan / románticas campanas”); o endecasílabos ("el silencio de mi íntimo tormento / fantasmea paisajes... las lejanas / infiltraciones de la noche esfuman / los perfiles como un ala cansada”). Versos dominados por un paisaje, curiosamente, silencioso. La palabra silencio, como una especie de nudo rígido de la memoria, se repite en los fragmentos de ambos poemas recordados.

Una segunda edición de la obra de Juan L. Ortiz deberá plantearse el problema de estos años oscuros, los que borran justamente la fisonomía del joven poeta Ortiz para elaborar la del adulto. Hay varios indicios y testimonios que nos ayudan a aproximarnos a esa imagen, en estos casos a partir de una mirada exterior. Tenemos por ejemplo el testimonio de Salvadora Medina Onrubia, publicado en la revista Fray Mocho en 1914:

¡Algo de bello!... Ortiz es más artista con la pluma que con el lápiz. Sin embargo, son versos malos, a veces tienen ripios, chocan... Con ideas hermosas que llegan a los nervios. Versos llenos de rugidos. A veces una palabra rebuscada... "Pero eso no importa. Llegará. Vencerá”, decía yo.

Este texto, escrito los años en que Ortiz viaja a Buenos Aires, es importante en función de su fuente. Salvadora conoció personalmente a este joven poeta de dieciseis o diecisiete años, cuando trabajaba en Gualeguay como maestra.

Por otra parte hemos encontrado un poema publicado en 1912, es decir, a los dieciseis años del poeta, que se corresponde en cierto modo con la descripción anterior ("versos llenos de rugidos”). Un poema que se llama precisamente "Mi grito”, compuesto de tres cuartetos de versos endecasílabos, con rimas consonantes. Termina así:

¡Oh, los cultos hipócritas que miran

La inocencia del Arte como a impura!

Yo los ahorcaré, en mis estrofas,

Con el nudo triunfal de mi locura. ${ }^{6}$

Los dos primeros versos enlazan, curiosamente, los tópicos de la “inocencia”, “impureza” o "locura”: distintos lugares comunes que forman parte del imaginario del joven poeta. La voz poética encarna, por otra parte, el último eslabón: "la locura” y la misma es presentada como triunfo. Todos estos elementos están ligados también al

6 Publicado en El Debate, Gualeguay, el lunes 11 de noviembre de 1911. Firmado de la siguiente manera: "Juan L. Ortiz. Gualeguay, 6-11-1912". Si la fecha que figura al pie del poema es la de su escritura, o al menos de su última corrección, es curioso que no haya mucha distancia entre escritura y publicación.

Revista Iberoamericana, Vol. LXXX, Núm. 246, Enero-Marzo 2014, 205-225
ISSN 0034-9631 (Impreso) 2154-4794 (Electrónico) 
estereotipo del poeta-joven que viene del romanticismo y que encarna perfectamente un poeta como Gerard de Nerval, importante en la formación de Ortiz.

Tenemos entonces un testimonio y un ejemplo de lo olvidado. Es muy difícil que se hayan conservado manuscritos de esta etapa -no se encontraron todavía-, pero esta posibilidad no puede descartarse. Otros ejemplos podrán aparecer en publicaciones de la época. De todos modos con este poema podemos comprobar la existencia de un "grito" y de la necesidad de silenciarlo y elaborar desde ya algunas hipótesis, provisorias sin duda, sobre el significado de ese "silencio".

LOS MIL Y UN POEMAS DEL JOVEN SAER

Saer intentó construir, desde el inicio de su trabajo de escritor, una determinada imagen de poeta en la cual la “iniciación” cumple una función primordial. Es difícil saber si se pensaba a sí mismo, al comienzo, más como poeta que como narrador -o poeta y narrador en la misma medida-, porque es el narrador, cuando consolida su proyecto -es decir a mediados de los años 70-, el que regresa al momento de la iniciación para poner en relieve la importancia del poeta. Y luego, aunque el desarrollo de su trabajo de escritura fue privilegiando la prosa, lo "poético", la condición de "poeta”, o si se quiere una imagen propia de poeta, nunca fue abandonada totalmente. En este marco debemos estudiar la aspiración de Saer a la confusión de géneros y formas, principalmente entre la novela y el poema, tema sobre el que vuelve constantemente en ensayos y reportajes, proponiendo, en cierto modo como programa, la búsqueda de una prosa poética, de un poema narrativo o de una novela en versos. Esta búsqueda implica, en gran medida, la construcción o reconstrucción de una imagen de joven poeta, una suerte de "autorretrato" retrospectivo incesante que además evoluciona con el tiempo, planteado menos con fines propiamente biográficos que, para decirlo en estos términos: "profesionales".

En un reportaje sin fecha, probablemente de 1980 (por lo menos anterior a 1983, ya que se menciona la escritura de El entenado), del que encontramos entre los papeles de Saer un dactilograma (se trata de la respuesta "escrita" a un cuestionario), Saer realiza grandes bocetos autobiográficos para delinear este estadio inicial de su escritura. Responde probablemente al pedido de un periodista o de un investigador pero es un texto que, según aclara Saer: "De ninguna manera está destinado a la publicación”. Allí habla de sus primeros pasos en la escritura: "A partir, pongamos, del 52, empecé a llenar cuadernos y cuadernos de poesías, de novelas policiales y de obras de teatro. Entre 1952 y 1957 no debo haber escrito menos de mil poesías”. Y habla también de sus primeras publicaciones: "Yo había empezado a publicar, de tanto en tanto, a partir de diciembre de 1954, poemas aislados en El Litoral".

Es sorprendente, aunque no inverosímil, que en la memoria de estos hechos, veinte o treinta años después de ocurridos, se destaque la preocupación por las fechas.

Revista Iberoamericana, Vol. LXXX, Núm. 246, Enero-Marzo 2014, $205-225$
ISSN 0034-9631 (Impreso) 
Volveremos sobre este tema más adelante, pero en lo que se refiere a ese primer poema de 1954, efectivamente el domingo 5 de diciembre de ese año aparece en El Litoral "Motivos del canto", primer texto publicado de Saer del que tenemos conocimiento, que es un poema. Tenía entonces diecisiete años. ${ }^{7}$

“Motivos del canto" está escrito en versos alejandrinos, inspirado claramente en la poesía de José Pedroni, particularmente en aquellos libros del poeta radicado en Esperanza -ciudad de la provincia de Santa Fe celebrada como capital nacional de la colonización- que “cantan” el mundo agrícola. Reproducimos la primera estrofa:

Penetro en el dominio de la espiga madura sintiendo el río de oro ceñirse a mi cintura y olvidando el erial de la espina y el llanto surge como una aurora de voluntad el canto.

La relación iniciática del joven Saer con la persona y la obra de Pedroni está de alguna manera relatada (o más bien deberíamos decir revisitada) en el prólogo a la edición de la Obra poética de Pedroni que Saer escribió en 1999 (reconstruyendo un hecho ocurrido cuarenta años atrás):

Un sábado de invierno de 1953 o de 1954 (yo tenía 16 ó 17 años), después del almuerzo, tomé el colectivo de Esperanza y a eso de las tres y media o cuatro, ante una puerta que todavía hoy creo recordar con claridad, toqué el timbre, esperé tembloroso un momento, y cuando me abrieron y me invitaron a pasar, al transponer el umbral, entré a la vez en la casa de José Pedroni y en la literatura. (9)

No tenemos muchas noticias de aquellos mil y un poemas escritos en la juventud (recordemos el reportaje mencionado anteriormente: "Entre 1952 y 1957 no debo haber escrito menos de mil poesías”), pero conocemos los publicados en El Litoral (quince, aproximadamente). El último de esta serie, es "Rosa en la mano", poema publicado el domingo 17 de noviembre de 1957. Se trata de un soneto en versos endecasílabos, que termina así:

Yo te quería rosa en palma abierta, golondrina latiendo junto a huerta que desarrolla inúmeros procesos.

\footnotetext{
7 No encontramos en las carpetas de poesía de Saer ningún manuscrito de esos poemas, mucho menos los de El Litoral, pero es probable que haya guardado algunos recortes del diario. Encontramos en cambio una transcripción de los poemas de El Litoral (los principales), que surgen de las notas tomadas por Graciela Montaldo en una visita a Santa Fe, en 1984, para la preparación de su libro sobre El limonero real. En este conjunto no se encuentra "Motivos del canto".
}

ISSN 0034-9631 (Impreso) 
¡No, poesía, no, yo no quería

que fueses -general- lo que cubría

mi realidad, mis carnes y mis huesos!

Es indudable que aquellos primeros ensayos, ligados en el comienzo al sencillismo provincial de Pedroni, en los epígonos de la poesía posmodernista, van evolucionando hacia otros "calcos" u "homenajes". Los poemas de El Litoral (como representación pública de aquellos mil y un poemas perdidos), muestran de alguna manera el laboratorio donde el poeta se confronta con la forma poética tradicional (el soneto, el verso alejandrino o endecasílabo) y mide además sus influencias (Pedroni y el marco epigonal del posmodernismo). Hay un recorrido desde aquel motivo agrícola del canto del primer poema hasta este último, donde se representa la forma efímera de una poesía (rosa en la mano, golondrina) y la imposibilidad, o si se quiere la negación, de que la misma recubra toda la "realidad" del poeta. Tanto en el primer poema como en el último, el tema es el origen de lo poético. En el segundo caso la poesía está casi personificada (“¡No, poesía, no, yo no quería / que fueses...!”) y es interpelada por el sujeto poético, entre signos de exclamación, respecto a la relación entre lo poético y la "realidad" del poeta ("mi realidad”). Llama la atención esa suerte de ripio, entre guiones ("general”), que acentúa en cierto modo la ironía o si se quiere la humorada de este último soneto de la serie de El Litoral.

Hacia este año de 1957, en que se publica este soneto, Saer conoce a Juan L. Ortiz, quien ocupará, de ahora en más, el lugar de "maestro" iniciador que antes ocupaba Pedroni: "Cuando [conocí a Juan L. Ortiz], a mediados de los años cincuenta, en una librería de Santa Fe, ya estaba llegando a los sesenta años, y tenía un aspecto venerable que incitaba al respeto" (Saer, El río sin orillas 224).

Ninguno de estos mil y un poemas escritos entre 1954 y 1957 será incluido en El arte de narrar, libro que reúne la obra poética de Saer. El arte de narrar se va componiendo progresivamente, aumentando con cada nueva edición, y aunque aparece en la obra de Saer como un texto paralelo al ciclo narrativo de sus novelas y relatos, resguarda en cierto modo una suerte de núcleo de iniciación. Se ve claramente que el proceso de publicación de los poemas acompaña, como con retardo, el proceso de composición, constituyéndose al mismo tiempo en Diario y Memoria de la escritura. De la escritura de poemas, claro, pero también, como en un segundo plano, de la escritura narrativa. Arte poética/arte de narrar son caras de una misma moneda. El arte de narrar en ningún momento renuncia a la complejidad que tiene todo relato autobiográfico que se escribe día a día pero que se organiza y publica retrospectivamente. Por otra parte el fondo de manuscritos y dactilogramas que Saer conserva consigo no contradice el carácter antológico, como de inventario, que tiene este libro (proponemos esta hipótesis provisoria).

Si bien Saer escribe poemas y los publica de manera dispersa, como vimos, desde por lo menos 1954, recién empieza a pensar y concebir el conjunto de su obra poética

Revista Iberoamericana, Vol. LXXX, Núm. 246, Enero-Marzo 2014, $205-225$
ISSN 2154-4794 (Electrónico) 
a partir de la publicación en 1970, en los Cuadernos Hispanoamericanos de Madrid, de catorce poemas reunidos bajo el título de "Poetas y detectives". ${ }^{8}$ Estos poemas van a constituir el grupo inicial de El arte de narrar, dado que todos serán incluidos luego en el libro. Pero El arte de narrar no existía todavía como proyecto en 1970, sino de manera embrionaria. La primera edición aparece en Venezuela en marzo de 1977 (Caracas, Fundarte) y lleva como subtítulo “Poemas. 1960-1975”. El año inicial, 1960, es el mismo en el que Saer publica En la zona, libro de relatos con el que comienza a construir su ciclo narrativo.

Es interesante destacar, en el proceso de definición del libro -como lo ha estudiado Martín Prieto-, ${ }^{9}$ la corrección que realiza Saer en el título de un poema que en Cuadernos Hispanoamericanos se llamaba "Arte poética”. La corrección se ve claramente en un dactilograma, donde el poema está fechado en 1969 (ni en la revista ni en el libro aparece la fecha) y donde se corrige el título “Arte poética” por el de "El arte de narrar” (ver Figura 1). La corrección, indudablemente, es posterior a 1969 (fecha del poema en

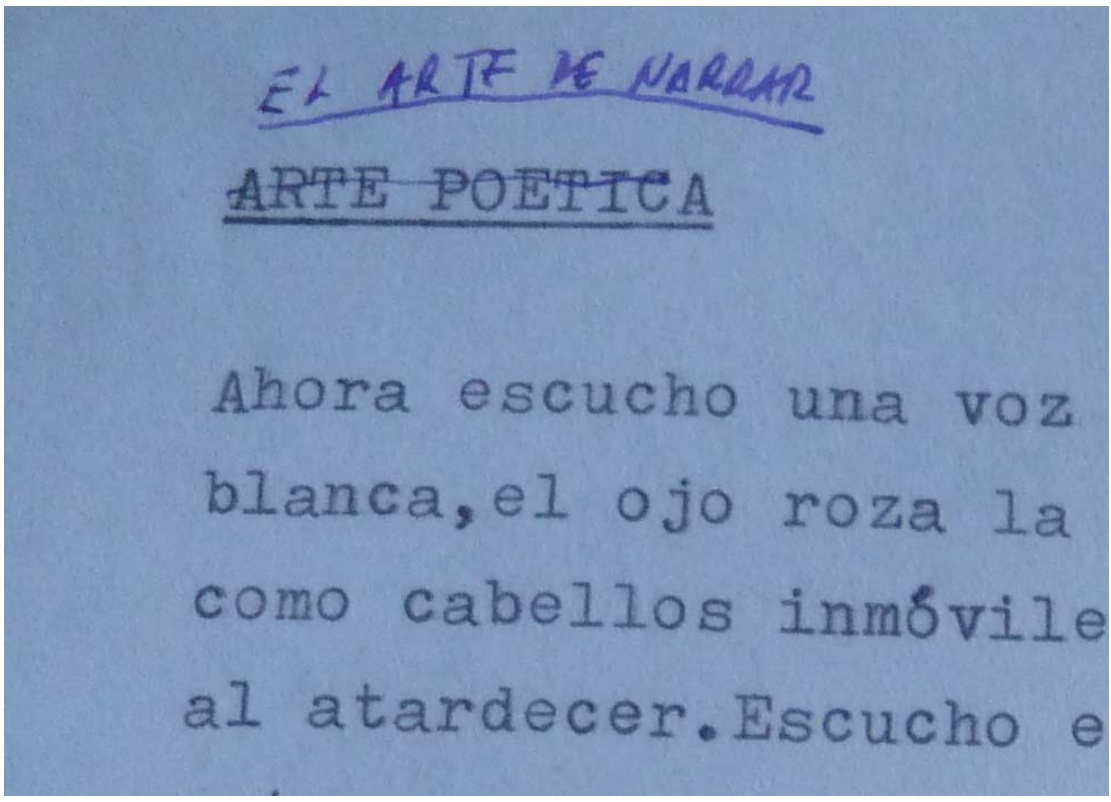

Figura 1: dactilograma del poema "El arte de narrar” (incluido en la primera sección de El arte de narrar) cuyo título original, “Arte poética” está corregido a mano.

8 El primer poema es "Recuerdos del doctor Watson”, lo que explica de alguna manera el título. Siguen, en este orden: "De 'L’art romantique’”, la trilogía "Dante”, "Dylan Thomas in America”, "A Francisco de Quevedo", “Babilonia”, “Motivos”, “Octubre en Tostado”, “A una cabeza de Safo de Lesbos”, "Por Clodia (Lesbia) en el cabaret”, “Arte poética”, "He weeps over Jim”.

9 Ver “En el aura del sauce en el centro de una historia de la poesía argentina”, Obra completa 120.

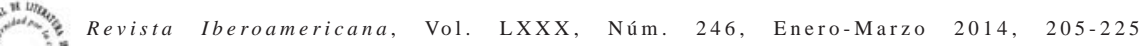
ISSN 0034-9631 (Impreso) ISSN 2154-4794 (Electrónico) 
el dactilograma), pero también posterior a 1970 (fecha de publicación en Cuadernos Hispanoamericanos). Se realiza, en realidad, en algún momento entre 1970 y 1976, que son los años en los que se consolida el proyecto de El arte de narrar (libro que fija su fecha de inicio, como dijimos, en 1960) y también los años en que se define el proyecto narrativo (entre 1970 y 1976 se decide la escritura y la publicación de textos como La mayor, El limonero real y Nadie nada nunca). Según las fechas de los manuscritos, en este período, es decir a principios de la década del 70, se escriben la mayoría de los poemas de esta primera etapa de El arte de narrar.

En 1976, poco tiempo antes de la aparición de la primera edición de El arte de narrar, Saer escribe lo siguiente en respuesta a un reportaje:

Todos mis esfuerzos tienden más bien a borrar cualquier tipo de distinción [entre obra de narrador y de poeta]. Yo no he publicado nunca ningún libro de poesía, sino que he hecho publicaciones esporádicas de grupos de poemas. El título general de mis poemas que pronto aparecerán recopilados es justamente El arte de narrar. Yo trabajo en mis narraciones esporádicamente, sin ningún tipo de organización: por ejemplo, conozco narradores que trabajan todos los días de siete de la mañana a mediodía y de las tres de la tarde hasta las ocho. [...] El problema es que una narración crece con dificultad, que toda una serie de automatismos acechan al narrador, aparte de otros obstáculos de orden diferente, y que un trabajo demasiado organizado tiende a disminuir la vigilancia. Yo trato de poner la misma intensidad en un fragmento de narración que en un poema.

Acá se cierra entonces un momento de preparación, que puede remontarse a aquellos mil y un poemas, los publicados o los inéditos, pero sabiendo, como dijimos anteriormente, que ninguno de esos poemas será incluido en El arte de narrar. Saer esboza un proyecto poético que tiende a confundir (o borrar, para usar una palabra del vocabulario del autor) los límites entre el trabajo de escritura del poema y el de la narración. No hay diferencia entre ambas escrituras, dice: la intensidad es la misma. Completará esta idea, además, con la búsqueda del poema-narrativo, un poema por lo general extenso, aunque no necesariamente, que se compone en función de personajes literarios (aquí la clasificación de “poetas” y “detectives”, si bien insuficiente, refleja perfectamente la tipología de estos personajes poéticos, que sigue la estela de Pound y otros poetas de lengua inglesa). En el reportaje mencionado anteriormente, Saer pone como ejemplo de poema narrativo el "Gualeguay” de Ortiz. Hay que distinguir, sin embargo, en el marco de esta problemática de la confusión de géneros, el proyecto de escribir una "novela poética” o una "novela en versos". Este proyecto nunca fue concretado. En una nota en uno de sus cuadernos, cuyo título es "Sobre la novela poética”, que debe ser, dice, “al mismo tiempo realista y alegórica”, Saer tienta una genealogía: "la Ilíada, la Odisea, De Rerum Natura, La Divina Comedia, el Fausto”. Aquí tampoco el proyecto se pretende como original. Lo original en Saer, en todo caso,

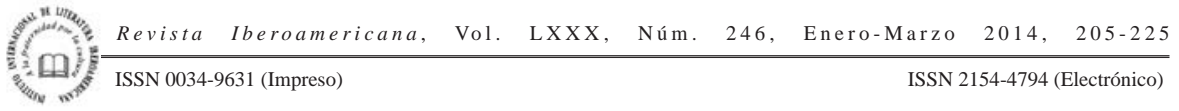


reside en la estrategia de fundar un universo narrativo a partir de un proyecto poético, en cuyo pasado se funde el presente, o donde el presente funda el pasado (¿texto a un mismo tiempo “alegórico" y “realista”?).

Insistimos sobre el carácter antológico de El arte de narrar. Lo que está en el libro es lo que ha quedado, o lo que resta, de un corpus mayor de poemas. Entre los manuscritos encontramos, en particular, dos proyectos de poemarios, dactilografiados y abrochados, que tienen un carácter fundacional: "Para cuerdas”, de 1960 (dedicado a Juan L. Ortiz) y "Continuo” de 1961 (dedicado a Aldo Oliva). Se trata de un primer esbozo de $E l$ arte de narrar, libro que en todas sus ediciones aparece dedicado "A Juan L. Ortiz y a Aldo Oliva”. A la luz de estos dos proyectos, distintos y sucesivos, la doble "a" de la dedicatoria, que resuena a redundancia, y que en todo caso plantea el carácter distinto y si se quiere intransferible de la deuda hacia la persona y la obra de cada uno de estos dos poetas, indica, además, una perspectiva más bien arqueológica.

El primer poemario está compuesto por ocho poemas, de los cuales pasan dos a El arte de narrar; el segundo por nueve poemas, de los que pasan a su vez dos. Es decir: de diecisiete poemas, quedan cuatro. Esta proporción, vale la pena señalarlo, más o menos se mantiene con el conjunto de los manuscritos. Si tomamos en cuenta solamente los poemas escritos a partir de 1960, se ve con claridad que El arte de narrar, en tanto libro antológico, se construye a partir de la selección. Sin hablar de la destrucción de poemas, tema del que en realidad poco se puede decir, aparte de recordar aquellos mil y un poemas de la juventud, entre los cuales algunos vestigios tenemos con los publicados en El Litoral.

El conjunto de ambos proyectos de poemarios ("Para cuerdas” y “Continuo”), al menos en sus títulos, parece regido todavía por esa voluntad de resaltar en la poesía sus aspectos musicales. Entre los poemas excluidos, hay un “Arte poética”, en dos versos:

La verdad: corazón triste, mano fría,

pálida rosa, en serio, sobre un deseo de ceniza.

En este breve poema se perciben rastros, más bien leves, como sedimentos -mano, rosa, deseo, ceniza- de "Rosa en la mano", el último poema publicado en El Litoral, del que hablamos anteriormente. Hay algo de lo pasado, sí, pero también se ve aquí otra cosa. En este primer ensayo de una definición poética, el canto como motivo va perdiéndose melancólicamente y, si volvemos al "Arte poética” de 1969 (título, insistimos, con el que fue publicado en Cuadernos Hispanoamericanos), observamos también que esta pérdida o borradura sigue una misma línea de transformación de la voz lírica en materia escritural: "En la hoja / blanca, el ojo roza la red negra que brilla". En El arte de narrar, hay en total tres poemas que se proponen como "Arte de narrar" y todos presentan variaciones al tema de la escritura, en sus aspectos, si se quiere, más materiales o gráficos. El último de estos poemas comienza de esta manera:

Revista Iberoamericana, Vol. LXXX, Núm. 246, Enero-Marzo 2014, $205-225$
ISSN 0034-9631 (Impreso) 


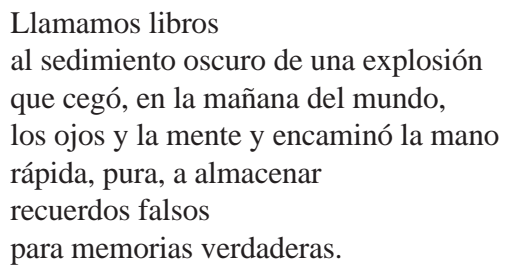

La poesía, como libro, va a ir componiéndose, en el marco del proyecto de El arte de narrar, de manera progresiva a través de cuatros ediciones y tres etapas. Cada una de estas ediciones demarca una escritura en proceso cuyo progreso, como veremos, parece ser más bien regresivo.

La primera edición, decíamos, es la de Venezuela, de 1977. La segunda se realiza diez años después, en Argentina (Universidad Nacional del Litoral, Santa Fe, 1988) y reproduce el texto de la edición anterior, sin variantes, que se organiza ahora en una primera sección: "El arte de narrar (1960-1975)”, a la que se le agregan dos secciones más: "Por escrito (1960-1972)” y "Noticias secretas (1976-1982)". Mencionamos rápidamente la tercera edición, bilingüe (L'art de raconter), en Saint-Nazaire (MEETArcane 17, 1990), que reproduce la anterior (la de la UNL).

Luego de las tres primeras ediciones, Saer pasa diez años sin agregar ningún poema a El arte de narrar. En un reportaje de 1994, cuando se le pregunta sobre el destino de su obra poética, Saer responde: “[...] desgraciadamente, en los últimos años no he escrito ningún poema. Yo dejo siempre cinco o seis poesías sueltas para que se encarguen de llamar a otras. Siempre escribí poesía por períodos y en 1986 escribí los últimos poemas, que aún permanecen inéditos, esperando una continuidad” (Russo 40).

La cuarta y última edición en vida de Saer se publica en 2000 (Buenos Aires, Seix Barral $)^{10}$ y refleja esta situación de parálisis de la escritura del poema. Se agrega a lo anterior una sección, con sólo seis poemas inéditos (seguramente algunos de los mencionados en el reportaje), bajo el título "La guitarra en el ropero. 1981-1987”). El título es por demás sugestivo si pensamos que esta sección cierra El arte de narrar como libro retomando el motivo del canto. Hay un poema inédito, de 1973, es decir que debería haber sido publicado antes, incluido por ejemplo en la primera sección, pero que es dejado de lado, que tiene ese título de "La guitarra en el ropero". Debería estar al final, puesto que da el nombre a la última sección, pero esto es imposible porque Saer respeta de manera estricta su propia lógica, de orden cronológico, que rige la organización de El arte de narrar. Parece ser uno de esos poemas “que llaman a otros”. Es significativo que vuelve a traer, como cierre, este problema del canto que se extingue:

${ }^{10}$ En todos los casos, citamos a partir de esta edición.

ISSN 0034-9631 (Impreso) 
Muy poco, o nada, casi, por cantar, aunque días enteros pasen adelgazándose, y todo está, como continuamente, ahí: la mesa, el vaso, las mañanas.

Podemos ver, entonces, que en cada una de estas ediciones, el texto de El arte de narrar se va ampliando con la incorporación de distintas secciones de poemas. Pero a pesar de tratarse de una escritura en progreso, de la cual dan cuenta muy globalmente el marco de años establecidos por las secciones en que se organiza el libro, El arte de narrar desarrolla, como dijimos anteriormente, un mecanismo más bien regresivo. El primer período de escritura, el que va de 1960 a 1975, que comprende dos secciones: “El arte de narrar” y "Por escrito", incluye 58 poemas, más de la mitad de la totalidad del libro. Luego siguen "Noticias secretas (1976-1982)" con 33 poemas y "La guitarra en el ropero (1981-1987)” con 6 poemas. A este rasgo cuantitativo, por demás elocuente, hay que agregar, además, el hecho de que los poemas son cada vez menos extensos.

Esta detención del canto, de la vena lírica, hay que aclararlo, acompaña el desarrollo de la escritura narrativa. Si bien la construcción de la obra poética en Saer produce un movimiento regresivo, en sentido inverso avanza la escritura de la obra en prosa. Y aquí la importancia que cobra El arte de narrar, como decíamos anteriormente, en tanto Diario y Memoria del trabajo de escritura.

Detengámonos un momento en un tema que había quedado pendiente: las fechas de los poemas. Estudiando el Fondo de manuscrito se ve la preocupación de Saer por establecer, con la mayor fidelidad posible, el año de escritura de sus poemas. La fecha inscripta al pie de cada poema, se trate de un manuscrito o de un pasado en limpio (dactilografiado), como en un discontinuo álbum de fotografías o en un herbolario (pienso en el Rousseau de Les rêveries du promeneur solitaire: "no volveré a ver esos hermosos paisajes, esos bosques, esos lagos, esos matorrales, esas rocas, esas montañas, cuyo aspecto siempre me produjo una particular emoción: pero ahora [...] no tengo más que abrir mi herbolario y rápidamente él me transporta”, 122), esa fecha al pie del poema, decíamos, y también el poema en sí, establecen un nexo incesante entre la escritura y la vida del poeta. Por lo general Saer, como muchos poetas, incorpora sistemáticamente la fecha al poema una vez concluida su escritura. Este acto sitúa el texto en esa particular biografía personal que compone la historia de una escritura; pero también lo inmoviliza en el tiempo, lo que es importante en un poeta como Saer, que nunca "reescribe" un poema. Cuando vuelve al poema, algún tiempo después, muy pocas veces realiza correcciones y éstas nunca son importantes.

El tiempo que media entre la primera escritura del poema y su publicación, en general, es particularmente extenso y llega a los diez o quince años (de hecho en la primera edición de El arte de narrar, de 1977, se incluyen poemas escritos en 1960, que habían permanecido inéditos desde entonces). Muchas veces, en esta vuelta a esa fotografía o hierba seca que es el poema, es decir en el momento de la relectura o la

Revista Iberoamericana, Vol. LXXX, Núm. 246, Enero-Marzo 2014, $205-225$
ISSN 0034-9631 (Impreso) 
corrección, si acaso el poema no está fechado, el poeta tienta una fecha, aproximativa. El carácter tentativo se aclara con un signo de interrogación. Es lo que ocurre por ejemplo con la versión manuscrita del poema "Escrito en invierno", sobre el que Saer vuelve, ejecuta algunas pocas correcciones y agrega al final la fecha "1966” con signo de interrogación (Figura 2). Mantiene la interrogación incluso cuando pasa un poema

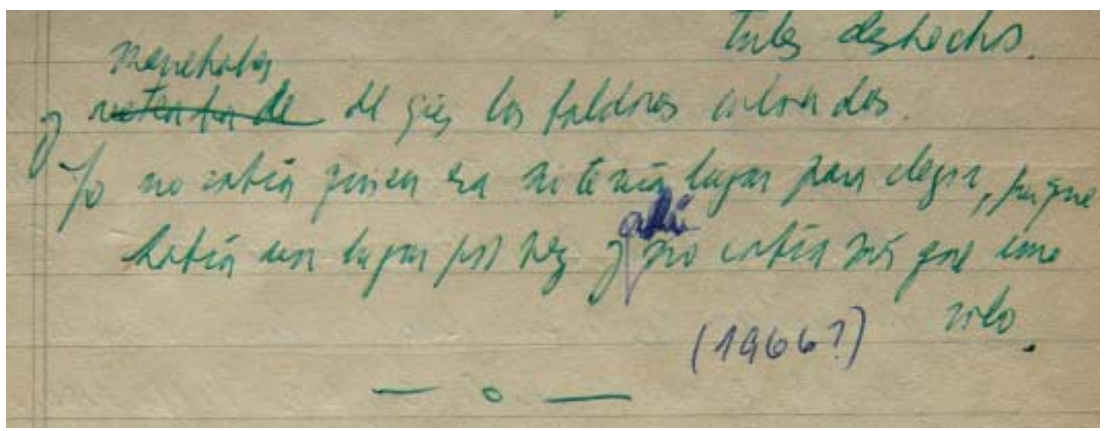

Figura 2: primera versión manuscrita, en un cuaderno, del poema inédito "Escrito en invierno". Saer vuelve sobre el poema años después y, entre otras correcciones, agrega la fecha. El poema está escrito con tinta verde, las correcciones con tinta azul.

a máquina, como es el caso de "Estrella, cuya raíz” (Figura 3). Y también, como última etapa de lo que parece ser, en realidad, un trabajo continuo y por momentos circular, a veces vuelve sobre un poema pasado en limpio, dactilografiado, como es el caso de

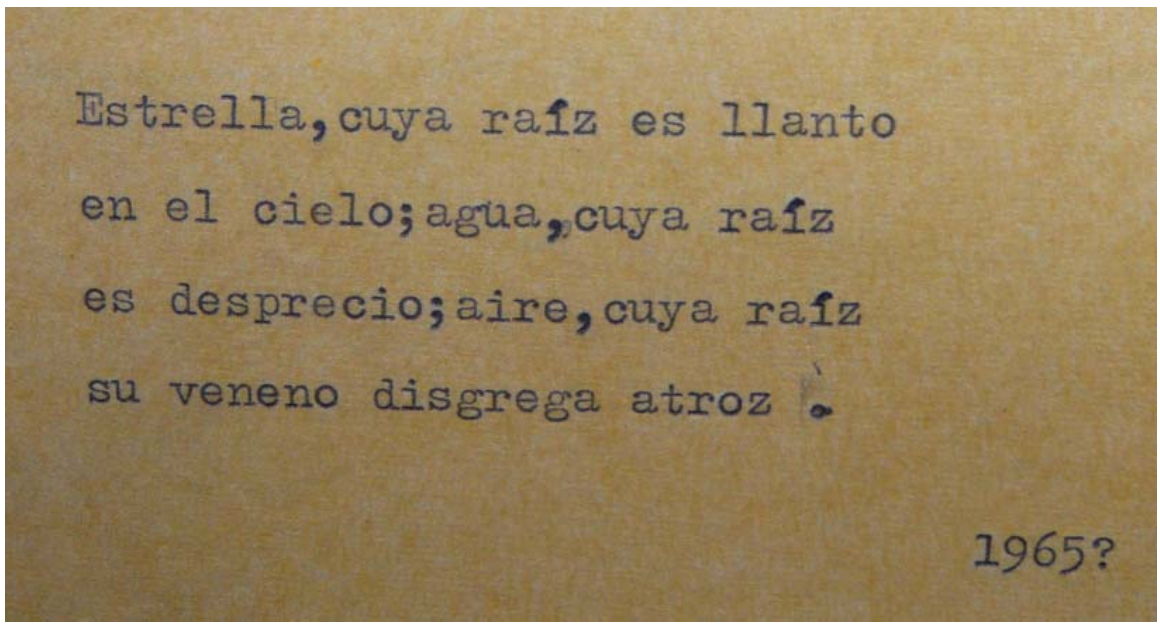

Figura 3: dactilograma del poema “Estrella, cuya raíz”, inédito.

Revista Iberoamericana, Vol. LXXX, Núm. 246, Enero-Marzo 2014, 205-225 ISSN 0034-9631 (Impreso) ISSN 2154-4794 (Electrónico) 
“Lo que cantan las sirenas”, y corrige a mano la fecha: “1969” por “1970” poniendo en evidencia que un texto, al menos en el caso del sistema literario de Saer, muchas veces se corrige hacia atrás (Figura 4).

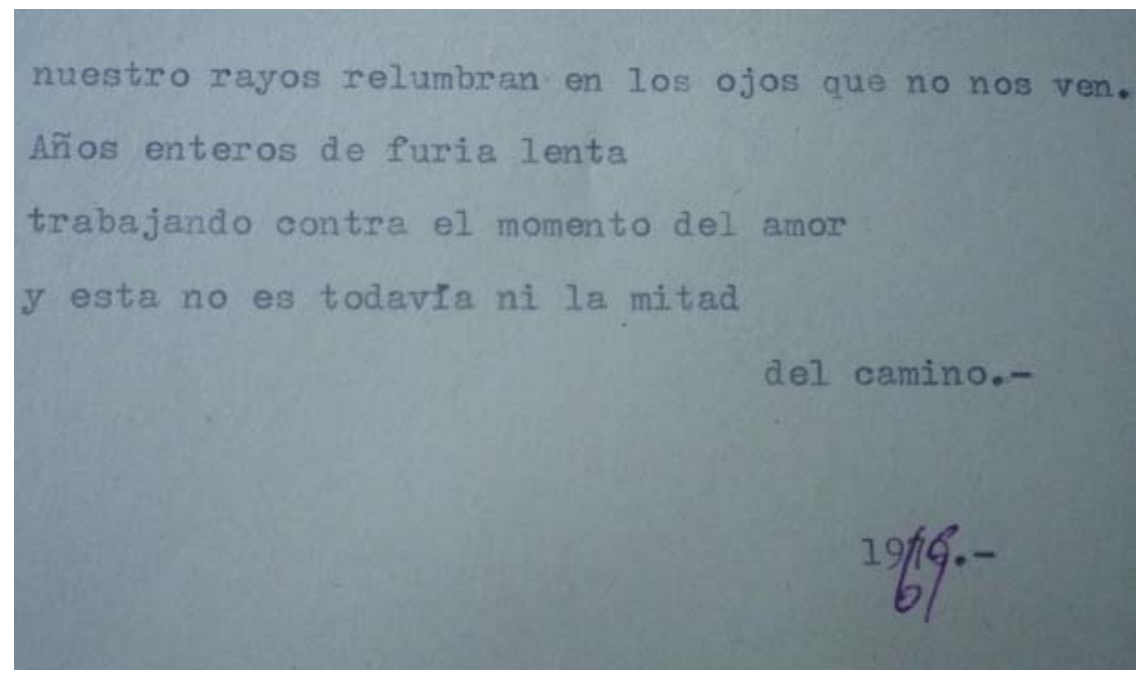

Figura 4: dactilograma del poema "Lo que cantan las sirenas” (incluido en El arte de narrar).

Almorir Saer no deja preparada ninguna continuación de El arte de narrar. Conserva sin embargo, en cuadernos y en carpetas, un volumen importante de poemas inéditos, manuscritos o mecanografiados. Muy pocos son posteriores a la última fecha del libro: 1987. Es decir que este corpus de poemas refleja, como una suerte de diorama, la parte oculta o si se quiere “apartada” de El arte de narrar. Una edición de estos poemas debe manejar con prudencia esta situación del texto.

Los poemas últimos, principalmente, no conforman una sección póstuma de $E l$ arte de narrar. Se trata más bien de poemas que "llaman a otros", es decir en la espera de ese otro poema, futuro, que Saer espera escribir o, si se nos permite el término: capturar. El símil no podía ser más feliz. Esta suerte de "llamador” que es el poema, evoca probablemente las cartas del juego, las que el jugador posee en la mano, a la espera de las por venir, en la dimensión de riesgo y azar que nunca abandona Saer en ese desafío constante que es su literatura, en particular la composición de versos. Pero evoca también, y quizás principalmente, esas jaulas dobles de la infancia, en uno de cuyos compartimentos se colocaba un pájaro cantor, para que llame a otros de su especie que, al aproximarse, vendrían a caer en la dulce trampa.

Revista Iberoamericana, Vol. LXXX, Núm. 246, Enero-Marzo 2014, 205-225 


\section{CONSONANCIAS Y DISONANCIAS}

Si retomamos nuestra problemática inicial, es decir las imágenes de “joven poeta” que se decantan en la poesía de Juan L. Ortiz y Juan José Saer, aparecen particulares consonancias y disonancias al comparar ambas obras. Quisiéramos, en el momento de lanzarnos a estas módicas generalizaciones, a las que estamos obligados considerando la hora de nuestro trabajo, que nuestros entrecruzamientos mantengan su cualidad ejemplar. Sin proponernos una conclusión definitiva -es improbable, además, que estemos con condiciones de hacerlo-, podríamos considerar un parámetro común de comparación, que podríamos considerar como la época, aunque preferimos llamarlo la edad. Pensemos entonces, para aplicarlo a nuestros poetas, en dos edades como horizonte de reflexión. En primer lugar la edad de 20 años, que es más o menos cuando el poeta comienza a escribir y se lo considera todavía -el poeta respecto a sí mismo y los demás respecto a su relación con la poesía- como un joven prometedor. En segundo lugar la edad de 40 años, cuando el poeta deja ya de "prometer” y comienza a entrar en la madurez entendiendo por este término el momento de "pasar a las cosas serias” y pensar en una obra-. Si ponemos en paralelo y combinamos estas dos edades en función de nuestros poetas -como el compositor de música de cámara que combina las voces distintas de, por ejemplo, un violín y un oboe-, veremos que se producen, de pronto y a un mismo tiempo, armonías y cacofonías singulares.

En Juan L. Ortiz, la edad de 20 años, es decir 1916, coincide con el año de la muerte de Rubén Darío. El dato podría ser o no relevante pero para un joven que entonces comenzaba a escribir, este hecho significaba algo así como el ocaso de un dios. Una anécdota podrá quizás ilustrar mejor esta idea: el joven Ortiz encuentra al poeta mayor en La Nación de Buenos Aires hacia 1913 -tenía en ese momento diecisiete o dieciocho años-. El joven merodeaba por los pasillos del diario y se encontró con un tío que trabajaba allí como cronista. Sesenta años después, Ortiz recuerda esta anécdota:

Yo me hice el desentendido y saludé tratando de parecer despreocupado ante mi tío. Pero él, dándose cuenta, me dijo con fina ironía: ‘Ah... ya andás vos por aquí... estás esperando a tus dioses...'. Y era realmente así. Aquella tarde y gracias a mi pariente hablaría nada menos que con Rubén Darío y su inseparable amigo Enrique Gómez Carrillo. (Perrone 36)

Nuestro joven poeta Ortiz comienza a escribir en esa época de tensiones entre el agotamiento de la forma poética modernista y la llegada del martinfierrismo. Recién a la edad de 40 años publica su primer libro y comienza a definir la fisonomía de su obra y su perfil de poeta maduro negando, como hemos estudiado, aquella primera y compleja etapa de iniciación.

\footnotetext{
Revista Iberoamericana, Vol. LXXX, Núm. 246, Enero-Marzo 2014, 205-225 ISSN 0034-9631 (Impreso) ISSN 2154-4794 (Electrónico)
} 
En Juan José Saer, la edad de 20 coincide con el contexto de la generación llamada del 50, principalmente la de los poetas nucleados en torno de la revista Poesía Buenos Aires, en tensión contra los últimos resabios del posmodernismo-entre los cuales Pedroni podría ser uno de sus representantes-, y es en estos años que encuentra a Juan L. Ortiz en una librería de Santa Fe. Este encuentro será fundamental, en lo que a la forma del poema se refiere, para decidir el abandono de la rima, la utilización del verso libre y comenzar a tensar la compleja red de voces que reside en toda su literatura, tanto en el poema como en la prosa. A los cuarenta años, es decir en 1977, exactamente, con un retardo paralelo al de Ortiz, pero que tiene un sentido totalmente diferente, Saer publica la primera edición de El arte de narrar, su libro de poemas.

Estas obras, absolutamente incomparables, por momentos parecen emanar de una fuente común y por momentos producen movimientos contrapuestos. La voz de Ortiz, que comienza con un grito, evoluciona borrando las marcas de esa juventud bohemia o rebelde, presentando una armonía equilibrada, "madura” si se quiere, o más bien desfalleciente, casi hacia el silencio, o trabajando con el silencio en tanto materia como pocas veces lo ha hecho la poesía argentina. Un silencio que interroga, incluso, las posibilidades de la resonancia de la voz más allá de la muerte (y el poema que vamos a citar a continuación pertenece al primer libro):

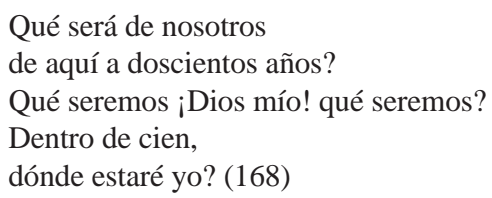

Saer, en cambio, necesitará ir hacia el pasado para reconstruir el futuro de su obra. No hay futuro para ese poeta cuya voz se ahoga en la obra haciendo emerger, como fuerza originaria, aquel momento mítico de su juventud. La obra poética de Saer comienza con una serie imitativa, en la que se interroga la fuerza y las posibilidades iniciales de lo lírico y avanza buscando, de manera paralela a la constitución del universo narrativo, una figura cristalizada de "poeta joven" con la cual identificar el momento inicial, anclado en el pasado, donde se tuvo una relación intensa con la poesía.

Así como la obra de Ortiz borra los rastros del joven poeta, la de Saer, por el contrario, necesita reencontrar ese rostro y mantenerlo como motivo y aspiración. Ambas voces trabajan desde el silencio o contra el silencio, en sentido muchas veces contrapuesto, perdiéndose y recuperándose en la caja de resonancia de la memoria.

Lo que acabamos de decir toca, esencialmente, el problema de los modos de construcción de la subjetividad poética. En otros trabajos estudié el proceso de selección que da origen a los primeros libros de En el aura del sauce, que se basan en la atenuación de esta subjetividad en un movimiento de fusión con el paisaje: "Rama de sauce soy..."

Revista Iberoamericana, Vol. LXXX, Núm. 246, Enero-Marzo 2014, $205-225$
ISSN 0034-9631 (Impreso) 
exclama esta voz, con optimismo, en un poema descartado (Protosauce, Obra completa 92); "Era yo un río" se permite, finalmente, algunos años después (El ángel inclinado, Obra completa 229). ${ }^{11}$ El poeta se relee y lo hace buscando su propia fisonomía poética. En el caso de Ortiz, Retrato y Paisaje se confunden en la representación de la subjetividad. En cuanto a la poesía de Saer, estudiando algunas líneas de la selección de poemas que da origen a El arte de narrar, comenzando con los dos poemarios "Para cuerdas" y "Continuo", pero incluyendo los poemas inéditos escritos posteriormente, puede verse claramente que en este trabajo de selección hay un "borramiento" del yo-lírico tradicional. El yo-poético instala en la poesía de Saer una zona de subjetividad muy difícil de determinar, donde voz, autor y autobiografía tienden a confundirse. Para dar un ejemplo podemos mencionar tres elegías, escritas entre 1960 y 1962, no incluidas en El arte de narrar, es decir que quedan de lado y permanecen inéditas, dedicadas a “G. L”, las siglas de una mujer que aparentemente murió o que al menos está alejada de la perspectiva del yo-poético, desaparecida de su vista. La sigla no permite descubrir la clave autobiográfica, pero a un mismo tiempo la recubre y la mantiene como enigma. Un nombre que se pierde entre papeles escritos:

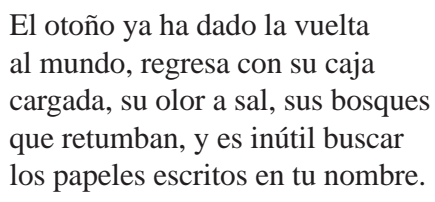

El núcleo de la obra poética de Saer, escrito entre 1960 y 1975, tanto el compuesto por los poemas éditos que se integran en las dos primeras secciones de El arte de narrar, como los inéditos fechados en este período, registra y, en cierto modo, atesora las alternativas de ese yo. Progresivamente el yo-lírico estalla en una galería sorprendente de alter-egos, a partir de una duplicación originaria: el personaje Carlos Tomatis, que representa la parte del yo que permanece en la Ciudad, en "la zona” y el personaje Pichón Garay que, vive exiliado en París, y representa la parte que se tuvo que ir. En este sentido, por ejemplo, dos poemas extensos enmarcan este movimiento: "Rubén en Santiago" en relación con Pichón Garay (el viaje en tren desde Montparnasse a Rennes) y "El fin de Higino Gómez” en relación con Carlos Tomatis (el suicidio de Gómez en un hotel de la ciudad). Ambos personajes como base, pero también tantos otros, coleccionan rasgos siempre dispersos y nunca demasiado precisos de proyección subjetiva: Petrus Borel, Carlos Baudelaire, el doctor Watson, Rubén Darío, Dylan Thomas, Safo, Turgeniev, Aldo Oliva, José y Rafael Hernández, Li Po, Polonio, Laertes, Quevedo, Dante, Crates,

${ }^{11}$ Ver "La obra de Juan L. Ortiz", introducción a la Obra completa (15-30) y también "El río interior”, introducción a El Gualeguay (7-56).

ISSN 0034-9631 (Impreso) 
Juan Moreira... Personas de la vida, personajes de la literatura que pueden emerger, por qué no, si mantenemos la dupla originaria -Tomatis y Garay-, a partir de la lectura de la literatura universal que hacen, por su parte, estos personajes. Es decir que las biografías de los personajes de El arte de narrar podrían leerse como trazadas, conversadas o escritas, a su vez, por cualquiera de esos personajes de las narraciones de Saer que se pasan el tiempo escribiendo o hablando de literatura (más hablando que escribiendo). Este proceso de enmascaramiento o, si se quiere, de disimulación, comienza con la selección de los poemas inéditos de El arte de narrar. Borrar para proteger el rostro del joven poeta y superponerle otra máscara.

¿Qué sentido tiene, en definitiva, todo intento de reconstruir un sistema que se erige como después de una destrucción? En uno de los poemas que llevan el título "El arte de narrar”, el origen mismo de una obra se plantea a partir de una dispersión de fragmentos:

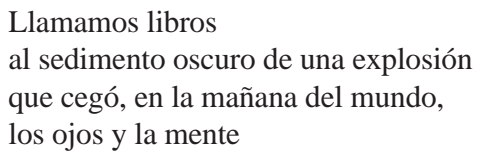

¿Qué mañana, la de qué mundo, fue cegada por esa explosión y qué explosión esa de cuyo sedimento nacen los libros? Son probablemente las mañanas que vivió el joven poeta que comenzó escribiendo aquellos mil y un poemas.

\section{OBRAS CITADAS}

Bignozzi, Juana. Reportaje a Juan L. Ortiz incluido en Juanele: Poemas. Buenos Aires: Carlos Pérez Editor, 1969. 117-40.

Medina Onrubia, Salvadora. "A caballo, a pie, a nado y en bote. Un pintor y poeta entrerriano que quiere hacerse célebre”. Fray Mocho (Buenos Aires, 6 de marzo 1914): 8.

Montaldo, Graciela. Juan José Saer: El limonero real. Buenos Aires: Hachette, 1986. Ortiz, Juan L. El Gualeguay. Edición, introducción y notas de Sergio Delgado. Rosario: Beatriz Viterbo Editora, 2004.

Obra completa. Edición, introducción y notas de Sergio Delgado. Santa Fe: Universidad Nacional del Litoral, 1996.

Pedroni, José. Obra poética. Prólogo de Juan José Saer. Edición de Sergio Delgado y Elisabeth Strada. Santa Fe: Universidad Nacional del Litoral, 1999.

Perrone, Alberto, “'Vivo metido «de patitas» en la vida y en la literatura”". Reportaje a Juan L. Ortiz. Siete días (Buenos Aires, 1976): 36-39.

Rilke, Rainer-Maria. Lettres à un jeune poète. Bernard Grasset y Rainer Biemel, trads. París: Grasset, 1937.

Revista Iberoamericana, Vol. LXXX, Núm. 246, Enero-Marzo 2014, $205-225$
ISSN 0034-9631 (Impreso) 
Rimbaud, Arthur. Une Saison en enfer. Poésies complètes. París: Livre de poche, 1984. Rousseau, Jean-Jacques. Les Rêveries du promeneur solitaire. París: Livre de Poche, 1983. Russo, Miguel. “Yo decidí volver a los orígenes, pero no para parodiarlos”. Reportaje a Juan José Saer. La maga (Buenos Aires, 2 de noviembre 1994): 40-41.

Saer, Juan José. El arte de narrar: Poemas (1960-1987). Buenos Aires: Seix Barral, 2000. El río sin orillas: Tratado imaginario. Buenos Aires: Alianza Editorial, 1991.

Revista Iberoamericana, Vol. LXXX, Núm. 246, Enero-Marzo 2014, 205-225 IST) 
